\title{
All-cause mortality in males with sleep apnoea syndrome: declining mortality rates
} with age

\author{
P. Lavie, L. Lavie and P. Herer
}

ABSTRACT: The objective of this study was to assess whether an increasing severity of sleep apnoea is associated with increased all-cause mortality hazards and to assess whether the syndrome is associated with excess mortality, in comparison with the general population.

Participants included 14,589 adult males, aged 20-93 yrs, referred to the sleep clinics with suspected sleep apnoea or diagnosed with sleep apnoea.

Altogether, 372 deaths were recorded after a median follow-up of 4.6 yrs. The crude all-cause mortality rate was $5.55 / 1,000$ patient yrs, increasing with apnoea severity. Cox proportional analysis revealed that both respiratory disturbance index (RDI) and body mass index significantly influenced all-cause mortality hazard but there was no interaction between them. Males with respiratory disturbance index $>\mathbf{3 0}$ had a significantly higher mortality hazard rate than the reference group of males with $\mathrm{RDI} \leqslant 10$. Comparing mortality rates of males with moderate/severe sleep apnoea to the general population revealed that only males aged $<50$ yrs showed an excess mortality rate.

The hazard of mortality in sleep apnoea increases with apnoea severity as indexed by respiratory disturbance index. Moderate and severe levels of sleep apnoea are moderately associated with an increased risk of all-cause mortality, in comparison with the general population, particularly in males aged $<\mathbf{5 0}$ yrs. The lack of information about possible confounders and treatment effects should be taken into consideration in the interpretation of these results.

KEYWORDS: All-cause mortality, body mass index, males, sleep apnoea

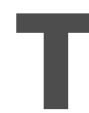
here is a large body of evidence linking obstructive sleep apnoea (OSA) syndrome with atherogenic processes [1-4], cardiovascular morbidity, in particular with hypertension [5-11], as well as with vehicle accidents and work-related accidents [12-13]. Although there have been reports of increased rates of mortality in sleep apnoea patients [14-16], these reports, based on small groups, did not examine the contributing role of obesity, nor the relationship with the severity of sleep apnoea syndrome. In this investigation, these questions were addressed by conducting a follow-up mortality study in a large cohort of males clinically evaluated by polysomnography because of suspected sleep apnoea syndrome. The relative mortality rates of these patients were also compared with the general male population in Israel.

\section{METHODS}

\section{Subjects and data}

During the study period (from January 1, 1991 to January 1, 2000), the Technion Sleep Medicine
Center, Haifa, Israel, comprised four sleep clinics with a total of 24 beds with recording equipment. Patients, referred because of sleep-related complaints, were clinically interviewed and examined by overnight polysomnography. The recordings included electroencephalogram, electro-oculogram, electromyogram and measurements of respiratory effort by a respiratory belt (SLP, Tel-Aviv, Israel), nasal-oral airflow by thermistors (SLP), and arterial oxygen saturation by a finger oximeter (Nonin, Plymouth, MN, USA). All clinics used the same recording equipment. Experienced technicians scored sleep records for sleep stages and respiratory events. Respiratory disturbance index (RDI) was calculated by dividing the total number of apnoeas plus hypopnoeas by hours of sleep. Respiratory disturbance index showed year-to-year stability with yearly means ranging $23-25$ events $\cdot h^{-1}$. The present analysis is based on data of adult males aged $>20$ yrs who underwent a whole-night sleep study because of symptoms suggestive of sleep apnoea, or with a laboratory finding of RDI

\section{AFFILIATIONS}

Lloyd Rigler Sleep Apnoea Research Laboratory, B. Rappaport Faculty of Medicine, Technion-Israel Institute of Technology, Haifa, Israel.

\section{CORRESPONDENCE}

$P$. Lavie

Lloyd Rigler Sleep Apnoea Research Laboratory

B. Rappaport Faculty of Medicine Technion-Israel Institute of Technology

Haifa

Israel

Fax: 97248293200

E-mail: plavie@tx.technion.ac.il

Received:

April 302004

Accepted after revision: November 182004 
$>10$. As the number of females investigated was considerably lower than males, this study focuses on mortality of males only. The local human subject ethics committee approved the study.

\section{Mortality}

Each participant's personal identification (ID) number (a unique 9-digit number assigned to every Israeli citizen) was used to collect mortality information from the computerised files of the Ministry of the Interior. Identification numbers of all participants who were studied in the sleep clinic after January 1, 1991 and before 31 August 31, 2000 were searched and date of death for participants who died were obtained. In addition to the vital status, the registry includes the following information: sex, date of birth, date, place and cause of death. The cause of death that was assigned according to the international classification of diseases-9th edition was available only for $61 \%$ of the deceased patients. Analysis of the specific causes of death will be performed at a later date.

\section{Analytical methods}

To examine the association between RDI, body mass index (BMI; weight $(\mathrm{kg}) /$ height $\left.(\mathrm{m})^{2}\right)$ and all-cause mortality, patients were stratified into three BMI groups, based on the National Center of Health statistics categories [17], and five RDI groups. The BMI categories included: recommended weight (BMI 20.7-27.7), overweight (BMI 27.8-31.0) and obesity (BMI $\geqslant 31.0$ ). The RDI groups included: $\leqslant 10$ (nonOSA), 11-20 (mild), 21-30 (mild-moderate), 31-40 (moderate) and $>40$ (severe). From among the participants in the study a group of 195 underweight males (BMI <20.7), one of whom died, were not included in this analysis. Crude mortality rates were calculated for cross-classified $\mathrm{BMI} \times \mathrm{RDI}$ groups by means of the number of deaths per 1,000 patient-yrs. Next, the Cox proportional Hazards model was used to calculate hazard ratios and the corresponding 95\% confidence intervals (95\% CI) for increasing RDI categories. Hazard ratios were adjusted for age and BMI. Males with RDI $\leqslant 10$ were used as a reference category. The proportional hazards assumption was verified by plotting the log of the negative log of the estimated survival functions against log time.
Patients' relative mortality rates were compared with the general population by computing person years at risk of death in 10-yr age groups $(20-29,30-39,40-49,50-59,60-69$ and $\geqslant 70 \mathrm{yrs}$ ) from males with a laboratory finding of RDI $>30$. This cut-off value was selected because categories of RDI $>30$ were associated with significantly higher mortality hazards than the reference group of males with RDI $\leqslant 10$. Similar analysis was performed for males with RDI $>50$ and RDI $<30$. The age distribution of the Israeli male population and mortality data extracted from the annual statistical reports for the same period were used as a reference group for the relative mortality rates analysis. To compare any two specific rates, a Poisson regression model for aggregate data was employed.

\section{RESULTS}

The survival status of 14,589 males with at least normal weight was ascertained, encompassing $90 \%$ of the total number of adult males that were eligible for this study. Altogether, $10 \%$ were lost to follow-up because ID numbers necessary for tracking data were missing or mistaken. Of the 14,589 males, the RDI and/or BMI of 736 patients were unknown and they were not included in the analysis. Mean age at sleep examination was 48.4 yrs (SD 12.3, range 20-93). The mean \pm SD of BMI was $28.8 \pm 4.8 \mathrm{~kg} \cdot \mathrm{m}^{-2}$ (range 21-64), and mean \pm SD RDI was $25.7 \pm 21.4$ events $\cdot h^{-1}$ (median 20). Median \pm SD follow-up period was $4.6 \pm 2.2$ yrs (interquartile range: 3.0-6.3 yrs; mean: 4.7 yrs). Prior to September 1, 2000, $2.6 \%$ of the males $(n=372)$ died. The RDI and/or BMI of nine of the deceased males were unknown. In regard to the deceased males, the mean \pm SD age when examined was $61.0 \pm 12.5$; the mean \pm SD age at death was $62.4 \pm 13.1$ yrs. The total number of observed patient yrs was 65,014 . Table 1 shows demographic data in the five RDI categories.

The crude all-cause mortality rate was $5.55 / 1,000$ patient-yrs, and increased with RDI $(\mathrm{p}<0.009$ for trend; table 2$)$. The highest mortality rate $(11.47 / 1,000$ patients-yrs) was observed in the obese group (BMI $\geqslant 31.0$ ) with RDI $>40$. Regression analysis revealed a significant linear increase in crude mortality in males at their recommended weight (test for trend $\mathrm{p}<0.02)$, and for the obese $(\mathrm{p}<0.05)$. A borderline

TABLE 1 Descriptive data of the 13,853 patients investigated in the Technion Sleep Medicine Center during 1991-2000 by five respiratory disturbance index $(\mathrm{RDI})$ categories

\begin{tabular}{|c|c|c|c|c|c|c|}
\hline & \multirow[t]{2}{*}{ Total } & \multicolumn{5}{|c|}{ RDI } \\
\hline & & $\leqslant 10$ & $11-20$ & $21-30$ & $31-40$ & $>40$ \\
\hline Cases n & 13853 & 3227 & 4154 & 2601 & 1204 & 2667 \\
\hline Median RDI & $20(11-33)$ & 7 & 15 & 24 & 35 & 59 \\
\hline Age at examination yrs & $48.4 \pm 12.3$ & $44.7 \pm 12.3$ & $48.1 \pm 12.0$ & $50.5 \pm 12.0$ & $51.2 \pm 11.6$ & $50.3 \pm 12.0$ \\
\hline Age at examination for deceased yrs & $59.7 \pm 13.1$ & $56.5 \pm 14.3$ & $60.6 \pm 12.5$ & $62.3 \pm 11.7$ & $64.2 \pm 11.8$ & $60.0 \pm 12.6$ \\
\hline Age at death yrs & $62.4 \pm 13.1$ & $59.1 \pm 14.5$ & $64.0 \pm 12.3$ & $65.6 \pm 12.1$ & $67.8 \pm 12.4$ & $62.9 \pm 12.6$ \\
\hline
\end{tabular}

Data are presented as mean \pm SD, as $n(\%)$ or as $n$ (interquartile range). BMI: body mass index. ${ }^{\#}$ : nine of the deceased patients did not have BMI and/or RDI and are not included. 


\begin{tabular}{|c|c|c|c|c|}
\hline $\begin{array}{cc}\text { TABLE } 2 \\
2 \\
\end{array}$ & \multicolumn{4}{|c|}{$\begin{array}{l}\text { Crude mortality rates per } 1,000 \text { patient-yrs based } \\
\text { on data from 13,853 patients investigated in the } \\
\text { Technion Sleep Medicine Center during } \\
\text { 1991-2000, for three body mass index (BMI) } \\
\text { categories and five respiratory disturbance index } \\
\text { (RDI) categories }\end{array}$} \\
\hline \multirow[t]{2}{*}{ RDI (median) } & \multicolumn{4}{|c|}{$\mathrm{BMI} \mathbf{k g} \cdot \mathrm{m}^{-2}$} \\
\hline & $\begin{array}{c}\text { Recommended } \\
\text { weight }\end{array}$ & Overweight & Obese & Total \\
\hline All & 4.77 & 4.79 & 7.64 & 5.55 \\
\hline$\leqslant 10(7)$ & 2.29 & 0.83 & 4.31 & 2.19 \\
\hline $11-20$ (15) & 3.80 & 4.44 & 6.48 & 4.52 \\
\hline $21-30(24)$ & 6.08 & 4.80 & 3.88 & 5.10 \\
\hline $31-40$ (35) & 9.23 & 8.47 & 7.86 & 8.57 \\
\hline$\geqslant 40(59)$ & 10.30 & 7.79 & 11.47 & 10.22 \\
\hline$p$-value for trenc & 0.02 & 0.08 & 0.05 & 0.009 \\
\hline
\end{tabular}

significant linear trend was found for the overweight $(\mathrm{p}<0.08)$.

In the Cox model, in which RDI and BMI were used as continuous variables, both were statistically significant (RDI: Chi-squared $=40.35, \quad p=0.0001 ; \quad$ BMI: Chi-squared $=10.44$, $\mathrm{p}=0.001$ ), without a significant interaction between them (Chi-squared $=0.37, p=0.54$ ). Using RDI as a categorical variable in comparing a group of males with RDI 11-20 to a reference group of males with RDI $\leqslant 10$ revealed that males in the RDI 11-20 group had a mortality hazard 52\% higher than the reference group; the BMI and age-adjusted mortality hazard rate for the group with an RDI of 21-30 was higher than that of the reference group by $34 \%$. These hazard rates fell short of statistical significance after Bonferroni adjustment for multiple comparisons (fig. 1). The age and the BMI-adjusted hazard ratio for males with an RDI of 31-40 was 2.13 (95\% CI, 1.36-3.34); for males with RDI >40 it was 2.59 (95\% CI, 1.733.87). Both hazard rates remained significant after adjustment for multiple comparisons. Regression analysis revealed a significant linear increase in mortality hazards with RDI $(\mathrm{p}<0.01$ for trend $)$.

To determine if the association of sleep apnoea with mortality was influenced by possible chronic illness at the time of diagnosis, the analysis was repeated after removing 428 males followed for $<1 \mathrm{yr}$, of whom 65 died during the sleep study. This revised analysis revealed nearly identical results. The hazard ratios, adjusted for age and BMI, were 2.18 (95\% CI, 1.33-3.57) and 2.49 (1.59-3.89) for males with RDI 31-40 and RDI $>40$, which remained significant after adjustment for multiple comparisons. As for the original cohort, there was a significant linear increase in mortality hazard with RDI $(\mathrm{p}<0.04)$.

\section{Relative morality rates}

From the entire population of 13,853 males, an RDI $>30$ characterised 3,871 (27.23\%) of patients, of whom $185(4.78 \%)$ died by August 31, 2000. Age adjusted all-cause mortality rate was no higher in males with RDI $>30$ than the general male

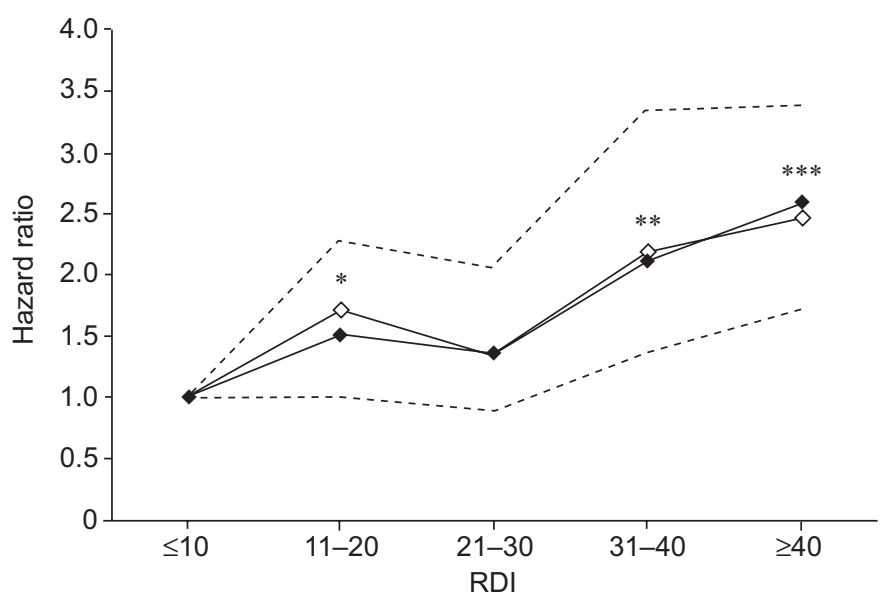

FIGURE 1. The association of age and body mass index-adjusted hazards of all-cause mortality with respiratory disturbance index (RDI) category referenced to $\mathrm{RDI} \leqslant 10$ for the entire cohort $(\diamond)$ and for males followed for at least $1 \mathrm{yr}(\bullet)$. - - $95 \%$ confidence intervals of the entire cohort. *: $p<0.05 ; * \star: p<0.01 ; * \star *$ : $p<0.0001 ; p$-values refer to both analysis and adjusted for multiple comparison 0.01

population $(0.91 ; 95 \% \mathrm{CI}, 0.79-1.05)$, but there was evidence of a different mortality rate in the three age groups (Chisquared $=37.41, \mathrm{p}<0.0001)$. Age-specific analysis revealed that relative mortality monotonically decreased with age. Only males aged 20-29 yrs had a significantly higher mortality rate than their counterparts in the general population (fig. 2). Their relative mortality rate was 5.84 (95\% CI, 1.45-23.42). Males aged 30-49 yrs had mortality rates that were higher than the general population, but of borderline statistical significance and males aged 50-79 had relative mortality rates that were close to the general population. Males aged $\geqslant 80 \mathrm{yrs}$ had mortality rates significantly higher than the general population (1.92; 95\% CI, 1.19-3.09). The significance level adjusted for multiple comparisons was 0.007 . Linear regression analysis

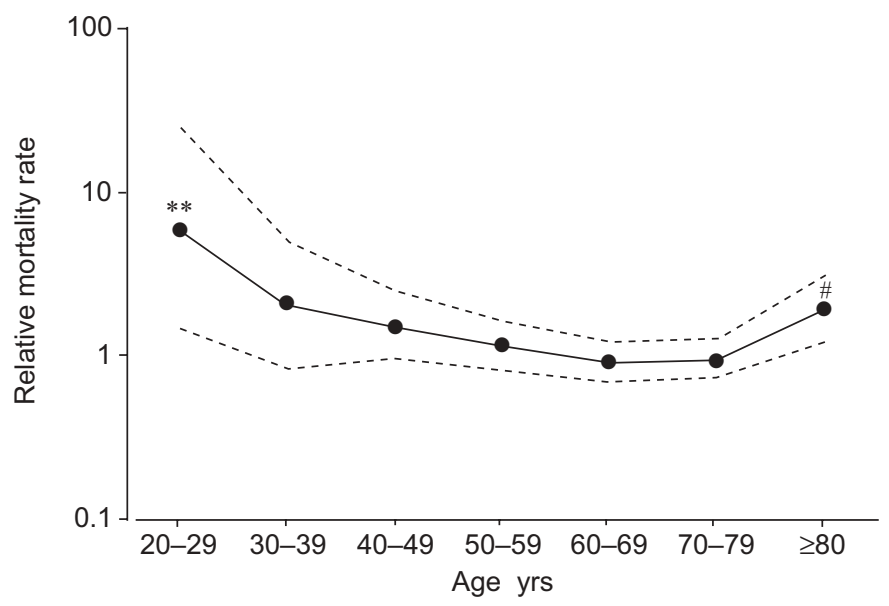

FIGURE 2. Relative all-cause mortality rates and $95 \%$ confidence intervals $(\mathrm{Cl})$ by $10-y r$ age groups in males with respiratory disturbance index $>30$ referenced to the corresponding mortality rates in the general population in Israel. - - - : 95\% Cl. **: $p<0.01$; $: p<0.007$; $p$-values adjusted for multiple comparisons 0.007 . 


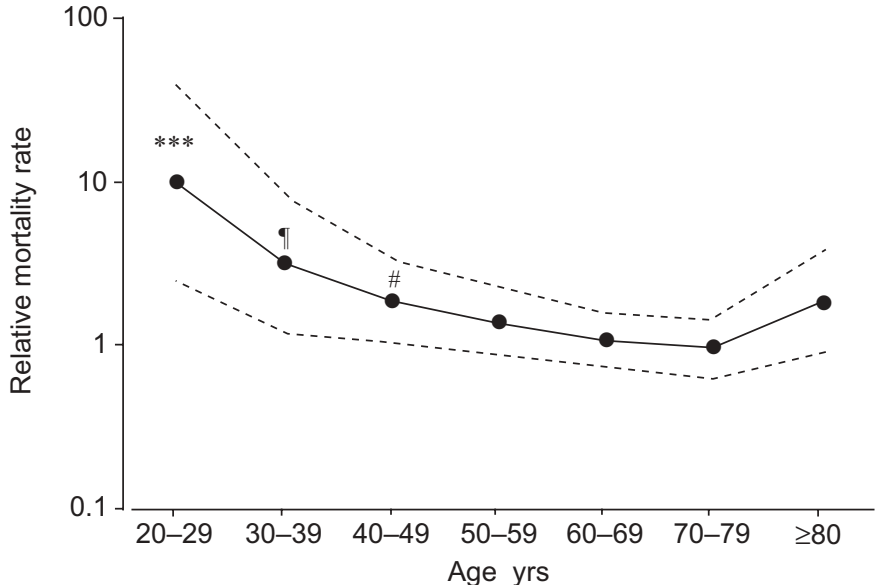

FIGURE 3. Relative all-cause mortality rates and $95 \%$ confidence intervals (Cl) by 10 -yr age groups in males with respiratory disturbance index $>50$ referenced to the corresponding mortality rates in the general population in Israel. $p$-Value

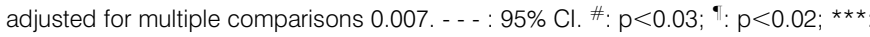
$p<0.001$

revealed a negative trend that bordered on statistical significance $(\mathrm{p}<0.06)$.

Similar findings resulted in an analysis restricted to males with even more severe sleep apnoea (RDI $>50$; fig. 3 ). This RDI characterised 1,909 patients of whom $95(4.97 \%)$ died. The ageadjusted mortality rate of males with RDI $>50$ was slightly higher than the general population $(1.11 ; 95 \%$ CI, $0.91-1.36)$ but this difference was not statistically significant. As before, there was a significantly different rate for the three age groups (Chisquared $=38.18, \mathrm{p}<0.0001)$. Males aged 20-29 yrs had a relative mortality rate of 9.8 (95\% CI, 2.44-39.25); males aged 30-39 yrs had a relative mortality rate of 3.12 (95\% CI, 1.17-8.35); males aged $40-49$ yrs had a relative mortality rate of $1.89(95 \% \mathrm{CI}$, $1.04-3.44)$. Males aged $\geqslant 50$ did not have any excess mortality. Linear regression analysis revealed a significantly negative trend $(\mathrm{p}<0.04)$.

In contrast to the above results, there was no excess mortality in patients with RDI $<30$ (fig. 4). This RDI characterised 9,982 patients, of whom 187 died $(1.87 \%)$. The age-adjusted mortality rate of males with RDI $\leqslant 30$ was lower than that of the general population $(0.51 ; 95 \% \mathrm{CI}, 0.43-0.60)$ but there was evidence of a different rate ratio in the different age groups (Chisquared $=13.08, p<0.001)$. Two age groups aged 50-59 and 6069 yrs had relative morality rates lower than the general population $(0.52,95 \% \mathrm{CI}, 0.38-0.72$ and $0.45,95 \% \mathrm{CI}, 0.34-0.59)$.

\section{DISCUSSION}

This paper describes the largest, by far, mortality follow-up study of males with sleep apnoea, encompassing a wide range of severities. Patients were investigated in four clinics in the same Sleep Medicine Center, using the same recording equipment and data analysis methodologies. The main findings are that an increasing severity of sleep apnoea was associated with a moderate increase in all-cause mortality hazards after adjustment for age and BMI, that this was particularly evident in moderate-to-severe RDI categories, and that only males aged $<50$ yrs with severe sleep apnoea had

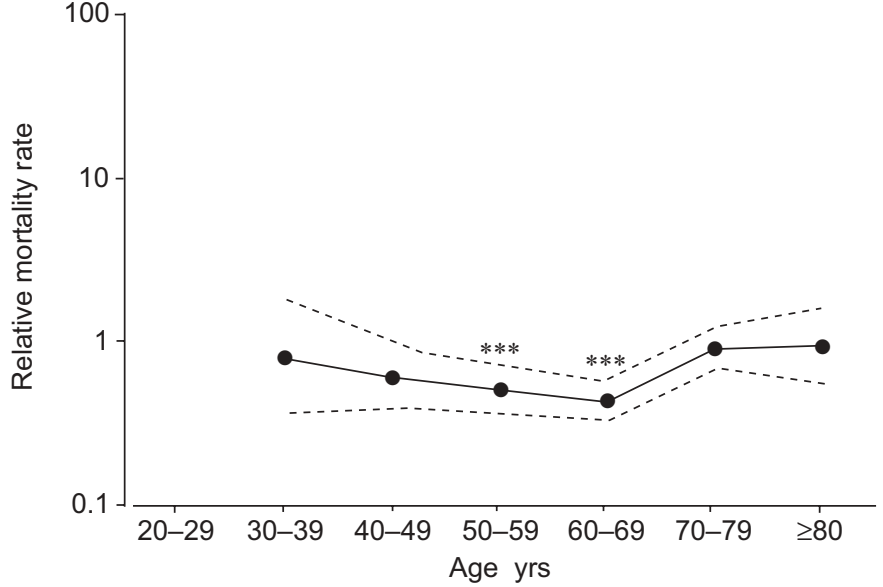

FIGURE 4. Relative all-cause mortality rates and 95\% confidence intervals (Cl) by $10-y r$ age groups in males with respiratory disturbance index $\leqslant 30$ referenced to the corresponding mortality rates in the general population in Israel. - - - : 95\% Cl. pValue adjusted for multiple comparisons 0.007. ***: $p<0.0001$

excess mortality rates in comparison with their counterparts in the general population. BMI, a known mortality risk factor [18, 19], was significantly associated with mortality hazard but there was no interaction between BMI and RDI. This suggests that sleep apnoea and body weight have at least partially independent influences on all-cause mortality.

In the analysis of mortality hazard resulting from sleep apnoea, only age and BMI were controlled for. Other potential confounding factors that could affect the risk of mortality, most importantly patients' clinical condition at the time of diagnosis, and treatment of the syndrome, were not controlled in the study. The analysis was repeated after removing all patients followed for $<1 \mathrm{yr}$, in order to minimise the influence of including patients who were chronically ill at the time of diagnosis, and obtained identical results. But this did not provide an adequate control for the possible differences in medical history between patients with different severities of sleep apnoea. It is well-documented that by the time of diagnosis, sleep apnoea patients display a high rate of cardiovascular morbidity that significantly increases with apnoea severity $[7,20]$. Furthermore, several follow-up studies reported an increased incidence of cardiovascular morbidity in middle-age sleep apnoea patients who were free of such morbidity at the diagnosis [21-23], even without a change in apnoea severity [24]. Had additional potential risk factors been adjusted for, such as medical history at the time of diagnosis, smoking, alcohol consumption etc. the association between RDI categories and mortality hazards would most probably be lower than the findings show. Thus, mortality hazard ratios associated with the RDI categories 11-30 that only bordered on statistical significance would possibly move toward 1.0 after adjustment for additional relevant risk factors. Previous sleep apnoea mortality studies in which adjustment to confounders, such as medical condition at diagnosis, was carried out did not find any association between mortality and the severity of the syndrome $[15,16]$. Since the current authors did not have reliable data on treatment outcomes, the influence of treatment on mortality was also not examined. Based on the results of the 
polysomnographic evaluation all patients found to have sleep apnoea were recommended treatment. In most cases, particularly in the moderate or severe, nasal continuous positive airway pressure (nCPAP) was recommended; weight reduction or upper airway surgery was also recommended if considered appropriate. Although the authors had information on all patients who underwent nCPAP titration procedure, it was not known how many actually complied with treatment. From several follow-up surveys conducted on nCPAP treatment in the authors' centre, the authors estimate that compliance with treatment was $\sim 50-60 \%$, which is similar to that commonly reported in the literature [25]. Likewise, the authors did not have information on the influence of upperairway surgeries or weight reduction protocols on the apnoeas.

The effect of treatment on mortality in sleep apnoea patients has not been widely studied. Veale et al. [26] reported that mortality of sleep apnoea patients treated with nCPAP was no different than the mortality of the general French population. Similar results were reported on a smaller group of French patients by CHAOUAT et al. [27]. In this study, however, nCPAP treated patients with underlying lung disease appeared to have higher mortality rates than the general population. In Spain, MARTI et al. [16], reported that mortality of untreated sleep apnoea patients was higher than that of the general population, and that treated patients did not show excess mortality. However, it should be noted that the mean age at death in the current study, 62.4 yrs, was not substantially different than the ages at death in all three studies that investigated mortality in patients known to be treated with nCPAP. These were 61.5 in VEALE et al. [26], 63.1 in Chaouart [27], and 63.0 in MARTI et al. [16]. Further well-controlled studies are needed to establish the effect of treatment on the longevity of sleep apnoea patients.

Another possible criticism of the current study is that the severity of the syndrome, left untreated, could have changed over time, meaning that the RDI at the initial diagnosis did not reflect the severity of the syndrome at the end. The few existing studies that investigated the natural evolution of sleep apnoea in untreated patients revealed conflicting results. Two studies reported that mild-to-moderate sleep apnoea may indeed progress in severity over a relatively short period of time, while three other studies reported that sleep apnoea is stable over time [24, 28-31]. Similarly, inconclusive results were reported in the elderly. PHODA et al. [32] and BLIWISE et al. [33] reported a mild increase in apnoea indices over a 3- and 5-yr period, respectively, while ANCOLI-ISRAEL et al. [34] found no change in RDI in a triple evaluation study over 8.5-yrs.

One of the most important findings of the current study is the association of mortality of sleep apnoea patients with age. Even in very severe sleep apnoea syndrome, with RDI $>50$, only males aged $<50$ yrs, particularly those aged 20-29 yrs, showed excess all-cause mortality in comparison with their counterparts in the general population. In this subgroup of males who had a median of 73 respiratory events per hour of sleep, the relative mortality rate for ages 20-29 yrs was 9.8, while it was close to 1.0 for ages $50-79$ yrs. Although it was also significantly higher than the general population in males aged $>80 \mathrm{yrs}$, this category included a small number of patients, 17 deceased and 14 living, which may indicate a chance finding. Although surprising, these findings are consistent with the results of all previously reported mortality studies in sleep apnoea. These studies, all based on much smaller samples than the present study [14-16], reported that sleep apnoea patients aged $<50$ yrs had the highest risk of mortality and that the risk declined considerably after age 50 yrs. Similar results were also reported in a 10-yr mortality study of males reporting habitual snoring and excessive daytime sleepiness, the two most typical complaints of sleep apnoea patients [35]. Finally, in two independent studies, ANCOLI-ISRAEL and collegues [36, 37] failed to find an association between sleep apnoea in the elderly and mortality.

The dramatic decline in the risk of mortality after the age of 50 is perplexing. Patients with severe sleep apnoea have additional risk factors, which could be expected to greatly exacerbate their risk of mortality. By the time of their diagnosis a substantial proportion suffer from cardiovascular morbidity [19-21]. An independent association between cardiovascular morbidity and breathing disorders in sleep was reported even for patients with a very mild form of disordered breathing in sleep, that falls within the normal range of 1-10 respiratory events per hour of sleep $[5,8,38]$. The majority of patients with severe sleep apnoea are obese, adding an independent mortality risk above and beyond that associated with cardiovascular morbidity and sleep apnoea [18, 19]. Of note, the mean BMI of patients with RDI >50 in the current study was $32.8 \mathrm{Kg} \cdot \mathrm{m}^{-2}$. Moreover, recent studies from the authors' own laboratory, and by others, have shown that sleep apnoea patients free of any cardiovascular disease have evidence of oxidative stress and inflammatory/immune cell activation, which may initiate atherogenic processes that cause accumulated damage to the vasculature [1-4]. This was also corroborated by reports that sleep apnoea patients free of any cardiovascular disease suffer from endothelial dysfunction, a subclinical state of atherosclerosis [39-41] that was shown to be predictive of future cardiovascular events $[42,43]$. All these risk factors could be expected to act synergistically to increase the risk of mortality in these patients.

What may be the explanation that in patients with a confluence of mortality risk factors excess mortality rates were found only in those aged $<50$ yrs? It is possible that this age-related decline in relative mortality represents a referral bias of performing diagnostic sleep recordings in younger sleep apnoea patients who were at a greater risk of death than the older patients. This could be due to more severe sleep apnoea in younger patients or to more comorbidities. Of note, the authors did not find a difference in sleep apnoea severity between younger and older patients, and if anything, younger patients had less comorbidities (data not shown). It is also possible that treatment of sleep apnoea masked the association between mortality rates and sleep apnoea in the older age groups. Thus, if relatively more patients aged $>50$ yrs were treated, it would reduce their apnoea severity and consequently also reduce mortality. However, this explanation appears unlikely in view of the fact that the same age-decline in mortality rates were also observed in a cohort of treated patients [26]. Finally, it is tempting to speculate that the age decline in relative mortality results from the fact that most sleep apnoea patients successfully adapt to the nightly apnoeic 
events by an as yet an unknown mechanism. Further studies are needed to verify this exciting possibility.

The present findings have immediate implications concerning the diagnosis and treatment of sleep apnoea. Currently, most patients are referred for sleep apnoea diagnosis in their fifth decade of life when symptoms are severe enough to disrupt their daily lives or to attract the attention of family members. In view of the fact that excess mortality in patients with severe sleep apnoea was found only for patients aged $<50 \mathrm{yrs}$, it is evident that diagnosis and treatment will be too late for many of the patients who are at maximum risk. Therefore, diagnosis and treatment of sleep apnoea should be done at the youngest possible age, which requires a more active approach towards diagnosis by sleep or other healthcare specialists.

\section{REFERENCES}

1 Lavie L. Obstructive sleep apnea syndrome-an oxidative stress disorder. Sleep Med Rev 2003; 7: 35-51.

2 Dyugovskaya L, Lavie P, Lavie L. Increased adhesion molecules expression and production of reactive oxygen species in leukocytes of sleep apnea patients. Am J Respir Crit Care Med 2002; 165: 934-939.

3 Lavie L, Vishnevsky A, Lavie P. Evidence for lipid peroxidation in obstructive sleep apnea. Sleep 2004; 27: 123-128.

4 Suzuki T, Nakano H, Maekawa J, et al. Obstructive sleep apnea and carotid-artery intima-media thickness. Sleep 2004; 27: 129-133.

5 Young T, Palta M, Hla KM, Finn L, Morgan B, Skatrud J. Population-based study of sleep-disordered breathing as a risk factor for hypertension. Arch Intern Med 1997; 157: 1746-1752.

6 Grote L, Hedner J, Peter JH. Sleep-related breathing disorder is an independent factor for uncontrolled hypertension. J Hypertension 2000; 18: 679-685.

7 Lavie P, Herer P, Hoffstein V. Obstructive sleep apnea syndrome as a risk factor for hypertension: population study. BMJ 2000; 320: 479-482.

8 Nieto FJ, Young TB, Lind BK, et al. Association of sleepdisordered breathing, sleep apnea and hypertension in a large community-based study. JAMA 2000; 283: 1829-1836.

9 Peker Y, Kraiczi H, Hedner J, et al. An independent association between obstructive sleep apnea and coronary artery disease. Eur Respir J 1999; 14: 179-184.

10 Mooe T, Rabben T, Wiklund U, et al. Sleep-disordered breathing in men with coronary artery disease. Chest 1996; 109: 659-663.

11 Peled N, Abinader EG, Pillar G, et al. Nocturnal ischemic events in patients with obstructive sleep apnea syndrome and ischemic heart disease: effects of continuous positive air pressure treatment. J Am Coll Cardiol 1999; 15: 1744-1749.

12 George CF. Reduction in motor vehicle collisions following treatment of sleep apnea with nasal CPAP. Thorax 2001; 56: 508-512.

13 Masa JF, Rubio M, Findley LJ. Habitually sleepy drivers have a high frequency of automobile crashes associated with respiratory disorders during sleep. Am J Respir Crit Care Med 2000; 162: 1407-1412.
14 He J, Kryger MH, Zorick FJ, Conway W, Roth T. Mortality and apnea index in obstructive sleep apnea. Experience in 385 male patients. Chest 1988; 94: 9-14.

15 Lavie P, Herer P, Peled R, et al. Mortality in sleep apnea patients: a multivariate analysis of risk factors. Sleep 1995; 18: 149-157.

16 Marti S, Sampol G, Munoz X, et al. Mortality in severe sleep apnea/hypopnoea syndrome patients: impact of treatment. Eur Respir J 2002; 20: 1511-1518.

17 VanItallie TB. Prevalence of obesity. Endocrinol Metab Clin 1996; 25: 887-905.

18 Calle EE, Thun MJ, Petralli JM, et al. Body-mass index and mortality in a prospective cohort of U.S. adults. $N$ Engl J Med 1999; 341: 1097-1105.

19 Dyer AR, Stamler J, Garside DB, Greenland P. Long-term consequences of body mass index for cardiovascular mortality: the Chicago Heart Association Detection Project in Industry study. Ann Epidemiol 2004; 14: 101108.

20 Kiely JL, McNicholas WT. Cardiovascular risk factors in patients with obstructive sleep apnea syndrome. Eur Respir J 2000; 16: 128-133.

21 Peppard PE, Young T, Palta M, Skatrud J. Prospective study of the association between sleep-disordered breathing and hypertension. $N$ Engl J Med 2000; 342: 1378-1384.

22 Peker Y, Hedner J, Norum J, Kraiczi H, Carlson J. Increased incidence of cardiovascular disease in middle-aged men with obstructive sleep apnea: a 7-year follow-up. Am J Respir Crit Care Med 2002; 166: 159-165.

23 Partinen M, Guilleminault C. Daytime sleepiness and vascular morbidity at seven-year follow-up in obstructive sleep apnea patients. Chest 1990; 97: 27-32.

24 Fisher D, Pillar G, Malhotra A, Peled N, Lavie P. Longterm follow-up of untreated patients with sleep apnoea syndrome. Respir Med 2002; 96: 337-343.

25 Lavie P. Treatment of sleep apnea: unmet needs. Chest 1999; 116: 1501-1503.

26 Veale D, Chailleux E, Hoorelbeke-Ramon A, et al. Mortality of sleep apnea patients treated by nasal continuous positive airway pressure registered in the ANTADIR observatory. Eur Respir J 2000; 15: 326-331.

27 Chaouat A. Mortality in treated sleep apnea syndrome. Rev Neurol (Paris) 2003; 159: Suppl. 11, 6S95-6S97.

28 Sforza E, Addati G, Cirignotta F, Lugaresi E. Natural evolution of sleep apnoea syndrome: a five year longitudinal study. Eur Respir J 1994; 7: 1765-1770.

29 Svanborg E, Larsson H. Natural evolution of obstructive sleep apnoea syndrome. Sleep 1993; 16: S124-S125.

30 Rosenthal L, Rohers T, Roth T. Natural evolution of sleep apnea: a two year follow-up. In: Kuna S, Suratt P, Remmers J, eds. Sleep and respiration in aging adults. New York, Elsevier, 1991; pp. 348-353.

31 Pendelbury ST, Pepin JL, Veale D, Levy P. Natural evolution of sleep apnoea syndrome: significant progression over a mean of 17 months. Thorax 1997; 52: 872-878.

32 Phoha RL, Dickel MJ, Mosko SS. Preliminary longitudinal assessment of sleep in the elderly. Sleep 1990; 13: 425-429.

33 Bliwise D, Carskadon M, Carey E, Dement W. Longitudinal development of sleep related respiratory 
disturbance in adult humans. I Gerontol 1984; 39: 290293.

34 Ancoli-Israel S, Kripke DF, Klauber MR, et al. Natural history of sleep disordered breathing in community dwelling elderly. Sleep 1993; 16: 525-529.

35 Lindberg E, Janson C, Svardsudd K, Gislason T, Hetta J, Boman G. Increased mortality among sleepy snorers: a prospective population based study. Thorax 1998; 3: 631-637.

36 Ancoli-Israel S, Kripke DF, Klauber MR, et al. Morbidity, mortality and sleep-disordered breathing in community dwelling elderly. Sleep 1996; 19: 277-282.

37 Ancoli-Israel S, DuHamel ER, Stepnowsky C, Engler R, Cohen-Zion M, Marler M. The relationship between congestive heart failure, sleep apnea, and mortality in older men. Chest 2003; 124: 1400-1405.

38 Shahar E, Whitney CW, Redline S, et al. Sleep-disordered breathing and cardiovascular disease: cross-sectional results of the Sleep Heart Health Study. Am J Respir Crit Care Med 2001; 163: 19-25.
39 Ip MS, Tse HF, Lam B, Tsang KW, Lam WK. Endothelial function in obstructive sleep apnea and response to treatment. Am J Respir Crit Care Med 2004; 169: 348353.

40 Kato M, Roberts-Thomson P, Phillips BG, et al. Impairment of endothelium-dependent vasodilation of resistance vessels in patients with obstructive sleep apnea. Circulation 2000; 102: 2607-2610.

41 Kraiczi H, Caidahl K, Samuelsson A, Peker Y, Hedner J. Impairment of vascular endothelial function and left ventricular filling: association with the severity of apneainduced hypoxemia during sleep. Chest 2001; 119: 1085-1091.

42 Heitzer T, Schlinzig T, Krohn K, Meinertz T, Munzel T. Endothelial dysfunction, oxidative stress, and risk of cardiovascular events in patients with coronary artery disease. Circulation 2001; 104: 2673-2678.

43 Bonetti PO, Lerman LO, Lerman A. Endothelial dysfunction: a marker of atherosclerotic risk. Arterioscler Thromb Vasc Biol 2003; 23: 168-175. 